\title{
VALOR SOCIAL DO TRABALHO NA CONSTITUIÇÃO FEDERAL DE 1988: INSTRUMENTO DE PROMOÇÃO DE CIDADANIA E DE RESISTÊNCIA À PRECARIZAÇÃO
}

\author{
SOCIAL VALUE OF WORK IN THE FEDERAL CONSTITUTION OF 1988: \\ INSTRUMENT OF CITIZENSHIP PROMOTION AND RESISTANCE TO INSECURITY
}

\author{
Jailton Macena de Araújo \\ Doutor em Ciências Jurídicas, área de concentração Direitos Humanos e \\ Desenvolvimento, pela Universidade Federal da Paraíba (2016). Mestre em Ciências \\ Jurídicas, área de concentração em Direito Econômico, pela Universidade Federal da \\ Paraíba (2011). Graduado em Direito pela Universidade Federal de Campina Grande \\ (2007). Atualmente é professor do Curso de Direito, vinculado ao Departamento de \\ Direito Processual e Prática Jurídica (DDPPJ), do Centro de Ciências Jurídicas (CCJ) da \\ Universidade Federal da Paraíba. E-mail: jailtonma@gmail.com
}

Recebido em: 12/09/2016

Aprovado em: 11/01/2017

Doi: $10.5585 /$ rdb.v16i7.478

RESUMO: O texto constitucional estabeleceu como fundamento da República Federativa do Brasil o valor social do trabalho, estabelecendo-o como princípio conformador da ordem jurídica. Por sua vez, o trabalho é mencionado sob o intento ético de assegurar dignidade e bem-estar social no contexto do Estado Democrático de Direito brasileiro. Ocorre, entretanto, que na sociedade do capital, o trabalho é subordinado a elementos exteriores de cunho econômico que acabam por impedir a sua efetividade, exaurindo-se nos empecilhos socioeconômicos que impedem a realização plena da cidadania. A essa evidencia, questiona-se: é possível reconhecer no valor social do trabalho a centralidade normativa capazes de contrapor a realidade hodierna de precarização e exploração pelo capital do trabalho humano? Parte-se da análise acerca das feições do valor social do trabalho reconhecendo-o como invólucro constitucional da proteção e do acesso ao trabalho, os quais se colocam como instrumento para a superação dos desafios decorrentes do contexto de crise econômica e de globalização pautada no modelo neoliberal de precarização dos direitos do trabalhador.

Palavras-chave: Constituição Federal de 1988. Valor Social do Trabalho. Proteção e Acesso ao trabalho. Precarização. Dignidade.

ABSTRACT: The Constitution provides the foundation of the Federative Republic of Brazil the social value of work, establishing it as a shaping principle of law. In turn, the work is mentioned in the ethical attempt to ensure dignity and social welfare in the context of the democratic rule of Brazilian law. It happens, however, that the capital of the company, the work is subordinate to external elements of economic developments eventually prevent their effectiveness, if exhausting us socioeconomic obstacles that impede the full realization of citizenship. By this evidence, the question is: is it possible to recognize the social value of work to rules centrality able to counter today's reality of casualization and exploitation of human labor by capital? It starts with the analysis about the features of the social value of work recognizing it as constitutional shell of 
protection and access to work, which are placed as a tool for overcoming the challenges arising from the context of economic crisis and globalization guided the model neoliberal of insecurity worker rights.

Keywords: Federal Constitution of 1988; Social Value of Work; Protection and access to work; Insecurity; Dignity.

SUMÁRIO: Introdução; 1. Perspectivas de promoção da cidadania pelo reconhecimento do valor social do trabalho; 2. Proteção e acesso ao trabalho: conteúdo e desafios à efetivação do valor social do trabalho;3. Precarização como contraponto fático à realização do valor social do trabalho; Conclusão; Referências.

\section{INTRODUÇÃO}

O texto constitucional brasileiro, no seu artigo $1^{\circ}, \mathrm{IV}$, apresenta como fundamento da República Federativa do Brasil o valor social do trabalho e, no artigo 170, caput, afirma que a ordem econômica é fundada na valorização do trabalho humano, trazendo ainda no artigo 193 que a ordem social tem como base o primado do trabalho.

Nos três casos, tanto na definição do Brasil como ente político constitucionalmente organizado, fundado no trabalho, bem como na afirmação de uma ordem econômica assentada na valorização do trabalho humano, e ainda na afirmação de uma ordem social baseada no primado do trabalho, revela-se a unidade do trabalho (ou do seu valor) como "princípio político constitucionalmente conformador (CANOTILHO, 2000)".

Além de revelar-se a intenção do legislador constituinte - que reverberava os clamores sociais pós-ditadura militar -, a articulação desses três momentos constitucionais em que o trabalho é expressamente mencionado apresenta, de modo claro, um intento ético, especialmente na ordem econômica, de "assegurar a todos existência digna", cujo objetivo, assinalado na ordem social, é "o bem-estar e a justiça sociais".

Dessa maneira, a construção do Estado Democrático de Direito brasileiro expressa-se realizada sobre o trabalho, como meio de produção e como valor humano, dotado de conteúdo dignificante. Ocorre, entretanto, que o valor trabalho, na sociedade do capital, é subordinado a elementos exteriores de cunho econômico que acabam por impedir a sua facticidade plena no contexto social.

O trabalho, como valor e como direito, acaba por exaurir-se nos empecilhos socioeconômicos que impedem a realização da dignidade. Nessa medida, impõe-se o seguinte questionamento: é possível reconhecer das faces do valor social do trabalho a essencialidade e a centralidade normativa capazes de contrapor a realidade hodierna de precarização e exploração pelo capital do trabalho humano?

Pretende-se, a essa evidência, reconhecer o valor trabalho como elemento dotado de validade constitucional, do qual se extraem as acepções de proteção e acesso ao trabalho e através do qual se estabelecem os parâmetros de resistência face a precarização. Nesse intento parte-se da análise metodológica dedutiva acerca das feições do valor social do trabalho reconhecendo-o como invólucro constitucional da proteção e do acesso ao trabalho, os quais se colocam como conteúdo e instrumento para a superação dos desafios decorrentes do contexto de crise econômica e de globalização pautada no modelo neoliberal.

É através do trabalho que são conferidas as oportunidades sociais de realização da cidadania no contexto social. Nessa esteira, o artigo está estruturado em três seções, além desta introdução: na seção 2, avaliamos o trabalho e o seu valor social, destacando que sua realização serve de perspectiva para concretização da cidadania social; na seção 3, é proposto o reconhecimento do valor social do trabalho a partir do seu conteúdo, fulcrado nas acepções de 
proteção e de acesso ao trabalho, como elementos capazes de superar os desafios à efetivação do valor trabalho; na seção 4, a precarização é apresentada como contraponto fático à realização do valor social do trabalho, em especial no contexto de crise(s) econômica e social.

\section{PERSPECTIVAS DE PROMOÇÃO DA CIDAdANIA PELO RECONHECIMENTO DO VALOR SOCIAL DO TRABALHO}

O valor social do trabalho têm suas origens no homem - portanto, em momento anterior à convivência em sociedade -, isto porque, embora seja mais próximo da razão do que do instinto, a sua realização já era ligada a mais primária e inafastável das necessidades, a sobrevivência.

O trabalho, como se percebe, está diretamente ligado ao bem maior que é a vida, uma vez que além de garantir subsistência, também é objeto de realização pessoal, e de inclusão social, possibilitando a interação dos sujeitos e garantido a integração do cidadão à sua comunidade. No sentido da interligação dos sentidos do trabalho com o sentido da vida, pode-se afirmar, sem receio, que o primeiro direito do homem é viver e o trabalho é uma das condições de vida do homem.

O trabalho, em sua evolução histórica, passou de atribuição do escravo à atividade econômica dotada de valor ético e social. Entretanto, como forma de mediação entre o homem e a natureza, o trabalho constituiu-se em uma ação humana, cuja importância individual não pode ser esquecida. Desse modo, não se pode negar também que ao lado do valor social do trabalho, na sua dimensão individual, o exercício laboral repercute na qualidade de vida de cada uma das pessoas envolvidas no processo de produção e participação na vida política e econômica da sua comunidade.

No processo de apropriação da natureza, o homem inicia a produção dos seus meios de vida e inicia o processo de "autodesenvolvimento", produzindo elementos que vão suprir suas necessidades imediatas e criando novas necessidades que tendem à complexificação (LARA, 2012, p. 205). Com isso, são exigidas novas ações do homem, no seu contexto de trabalho, que o compelem a reestruturar a sua própria vida social.

O trabalho nunca é algo fechado em si mesmo, mas um processo que exige avanços tecnológicos ou sociais, em especial em decorrência da ideologia econômica na qual está inserido. Quando à Constituição Federal de 1988, afirma-se que a sociedade brasileira constituise em um Estado Democrático de Direito, com fundamento no valor social do trabalho, no qual se estabelece um paradigma social para o Estado brasileiro que se assenta na promoção do sujeito do trabalho (o cidadão), de modo que sejam afastadas quaisquer compreensões que tencionem a exploração desumana dos indivíduos.

Embora se reconheça que há certa nebulosidade no sentido da expressão principiológica do valor social do trabalho, admite-se que a sua elevação constitucional a patamar de fundamento da República tenciona a construção da utopia de uma sociedade do trabalho, conforme mencionado por Habermas (1987).

O que se verifica, na verdade, é que os objetivos fundamentais do Estado Democrático de Direito são a valorização do trabalho humano e a redução das desigualdades regionais e sociais, que são nucleares no neoconstitucionalismo social plasmado na ordem jurídica pós 1988. O Estado Democrático de Direito, no contexto constitucional brasileiro, estabelece-se então como elemento primordial de proteção à pessoa humana.

O Estado Democrático, enquanto perfil político-jurídico dotado de um sistema (de princípios e regras) voltado a limitar e controlar o poder estatal e direcionar a esfera particular no 
sentido de concretizar o preceito da dignidade da pessoa humana - unificador dos valores sociais em prol do cidadão - desempenha papel primordial na esfera de proteção à dignidade.

O Estado Democrático de Direito brasileiro confere proteção aos direitos decorrentes da relação de trabalho, tais como os direitos de personalidade, direitos sociais e econômicos, relacionados à renda, previdência, educação, remuneração, descanso, lazer etc. proibindo-se quaisquer tipos de ações ou omissões que impliquem no rebaixamento ou na redução moral ou jurídica dos direitos do trabalhador. Reafirma-se, pois, do seu valor social que o trabalho humano não é um mero recurso econômico destinado à subsistência do sujeito, mas é, principalmente, um fator de promoção da dignidade humana e, como consequência, torna-se um fundamento para a promoção do homem e a expansão do bem-estar.

É nesse contexto de proteção que se estabelece a compreensão do valor social do trabalho (e da ação que é o próprio trabalho) como elemento de integração entre o trabalho e a dignidade. Nesse sentido, Jacobs (2001, p. 37), ao tratar da natureza das economias e dos processos que promovem a extinção ou a recuperação de aspectos importantes do trabalho, especialmente no que se refere aos mecanismos que levam à preservação ou à extinção de formas de trabalho, reflete sobre o sentimento de prazer e a "elevação do moral" a partir do trabalho.

Jacobs exemplifica ao apresentar a situação dos artesãos que desenvolvem a atividade de produzir tapetes na Turquia, os quais têm, ao serem reinseridos no processo cultural de recuperação de técnicas e valores antigos, a sua identidade preservada e o sentimento de dignidade resgatado:

[...] em algumas aldeias da Turquia estão sendo feitos tapetes orientais, tão maravilhosos quanto os mais antigos, graças a um conhecimento recuperado e que tinha sido quase perdido depois que as anilinas substituíram as tinturas naturais por volta de 1990. Além de criar cores mais sutis e mais vivas, as tinturas vegetais preservam melhor a lã. Além disso, aldeões que se tinham tornado ociosos quando os agressivos tingimentos químicos foram trazidos de fora, agora trabalham colhendo e preparando as plantas locais. Isso eleva o moral dos tecelões - que se se ressentiam contra os desocupados que nada faziam enquanto eles trabalhavam duro -, o que evidentemente aumenta a qualidade do tecido [...].

Resta claro, nesta passagem a importância da valorização do trabalho humano como instrumento de dignificação, que parte da necessidade de compreensão do desenvolvimento como processo global que envolve a todos, qualifica os sujeitos a participar do processo socioeconômico que promove a emancipação e a dignidade. Desse modo, além dos aspectos sociais e plurais que o trabalho assume, ele detém também uma dimensão de importância e dignificação individual que não pode ser eliminada do contexto social. O objetivo do trabalho passa a ser também, além da supressão das necessidades humanas (sejam elas materiais ou espirituais), o resgate da própria condição humana ligada à dignidade do trabalho.

$\mathrm{Na}$ realidade, o trabalho permite ao homem romper barreiras da individualidade, fazendo com que se diferencie no contexto social e possa, na relação social, colaborar com o outro. Nessa esteira, o problema que recentraliza a questão social em torno do embate capital $x$ trabalho, ganha novos contornos e significados com a globalização e a expansão cada vez mais forte das tecnologias e do mercado financeiro.

A globalização e a flexibilização dos instrumentos de proteção do trabalho passam a sofrer, especialmente em países em desenvolvimento, como o Brasil, novos ataques. É imperioso, pois, que o verdadeiro desafio socioeconômico, que é assegurar a efetividade do valor social do trabalho, de modo a promover uma maior abrangência e um impacto social de suas acepções protetiva e geradora de oportunidades sociais, seja reconhecido e colocado como pauta principal das lutas sociais para a superação da exclusão. 
É nesse sentido que a atuação protetiva do Estado deve ser maximizada como decorrência do pacto constitucional, exigindo que sejam firmadas verdadeiras cláusulas sociais ${ }^{1}$ internas, com o intuito de garantir um patamar mínimo de proteção fulcrado nos princípios base da Organização Internacional do trabalho (liberdade de organização sindical, negociação coletiva, eliminação da exploração do trabalho infantil, proibição do trabalho forçado e a não discriminação de trabalhadores, seja por raça, sexo ou qualquer outro fator).

A exclusão social, decorrente da negação de reconhecimento do valor social do trabalho, consubstancia verdadeira afronta aos direitos humanos a qual discrimina os mais pobres e os impede de alcançar o desenvolvimento. Nessa medida, o Estado deve atuar em várias frentes de modo a possibilitar que a frente precarizante não interrompa os processos de garantia de direitos e realização da igualdade (BRITO FILHO, 2004, p. 126).

Conforme pondera Russomano (2003, p. 30) “[...] a Lei Áurea aboliu a escravidão no Brasil e essa foi, sem dúvida, muito embora quase ninguém o tenha dito, a lei trabalhista mais importante até hoje promulgada no Brasil'”. Entretanto, em razão da forma como o trabalho é explorado e como a ideologia neoliberal tem delineado as políticas sociais no Brasil, os avanços sociais advindos desde Lei Áurea ainda parecem incipientes, em face da desproteção e da pobreza a qual sucumbem milhares de brasileiros.

O reconhecimento do valor social do trabalho, no contexto econômico atual, decorre da implementação das ações econômicas orientadas por um conjunto de normas pautadas numa elevação dos direitos sociais a um papel de centralidade, que fundamenta e corporifica o neoconstitucionalismo social. O que no Brasil, tem uma importância ainda mais clara, muito embora se perceba a onda conservadora que tem assolado a produção normativa brasileira.

Hodiernamente, o contexto de crise(s) política, econômica e social beira uma condição de caos social que tem afastado o trabalho dos espectros de luta e resistência que tradicionalmente ocupava. O homem bem como o seu contexto social acabam por modificar-se na medida em que é necessário haver transformações para que o trabalho seja realizado, mas mais importante é imprescindível que o trabalho seja recentralizado nos processos sociais e políticos.

A ideia de valorização do trabalho humano passa a sobrepujar da sociedade e a emanar preceitos morais que influenciam todas as esferas sociais, criando verdadeiras trincheiras contra os abusos do capital. É nesse sentido que Bocorny (2003, p. 42), reflete:

A valorização do trabalho humano, esclareça-se, não somente importa em criar medidas de proteção ao trabalhador, como foi destacado nos Estados Sociais. [...] o grande avanço do significado do conceito que se deu no último século foi no sentido de se admitir o trabalho (e o trabalhador) como principal agente de transformação da economia e meio de inserção social, por isso, não pode ser excluído do debate relativo às mudanças das estruturas de uma sociedade.

Assim, o capital deixa de ser o centro dos estudos econômicos, devendo voltarse para o aspecto, talvez subjetivo, da força produtiva humana.

No entanto, há quem entenda que a própria ideia de "valor social" do labor humano se reveste de um duplo significado. De fato, ao mesmo tempo em que o "princípio do valor social

\footnotetext{
1 A cláusula social é uma expressão cunhada no âmbito das relações do direito internacional. Seu surgimento é ligado, inicialmente, ao comércio internacional, com o intuito de garantir a aplicação de direitos fundamentais trabalhistas, já contemplados nas Convenções de base da OIT, nos contratos firmados entre Estados, ou entre determinado Estado e entidades privadas. Assim, a cláusula social deve ter a sua compreensão ampliada no sentido de realizar os direitos decorrentes do trabalho para a além das relações mercantis (sejam internas ou internacionais), garantindo a elaboração de mecanismos de proteção ao trabalho e de promoção de acesso. Nas palavras de Beltrana, deve "[...] haver o desenvolvimento de um sistema de relações do trabalho (regional), que tende a se sobrepor aos sistemas nacionais, mesmo que sem substituí-los, mas provocando influências recíprocas", garantindo a maximização da proteção decorrente do valor social do trabalho.
}

Revista de Direito Brasileira | São Paulo, SP | v. 16 | n. 7 | p. 115 - 134 | Jan./Abr. 2017 
do trabalho" funciona como exigência da humanização no plano das relações sociais e econômicas, ele atua, também, como uma ideologia que tende a obscurecer o fato de que, numa sociedade capitalista, qualquer que seja o modelo de organização da produção, o trabalho é incapaz de propiciar ao homem uma autêntica realização.

A ética weberiana de trabalho como condição de realização, na verdade parte da ideologia do capital, a qual passa a ofuscar a verdadeira relação existente entre o capital e o trabalho, nos termos descritos por Marx, em que o trabalho é considerado objeto da exploração e elemento de alienação. Todavia, não se pode deixar de traçar e reconhecer o panorama social que determina a centralidade do trabalho, mesmo na sociedade capitalista e global.

O trabalho permanece como o principal instrumento de inserção e de realização humana. A dignidade ainda é inserida e decorre da realização dos homens em suas atividades diárias, na qual o trabalho, sem dúvida, insere-se como instrumento primordial para fazer frente ao capital. Assim, o trabalho, mesmo reconhecido como parte do processo fetichizante e alienante do capital, jamais pode ser eliminado da ideia dignificante que o engloba.

Nessa medida, os direitos decorrentes do valor social do trabalho devem ser considerados em sua apreensão de solidariedade, através do qual o Estado e os particulares entre si estão vinculados ao seu cumprimento. Nas palavras de Arendt (1983), o trabalho é a chave de acesso à esfera pública, o qual promove o nascimento cidadão.

Esse surgimento cidadão, por sua vez, deve ser capaz de gerar o vínculo de comprometimento do homem com o mundo. Dessa ideia de comprometimento, decorre o espaço da cidadania e da solidariedade considerados de forma relacionada. A cidadania enquanto compreensão solidária está atrelada diretamente ao valor trabalho, por ser o trabalho o mecanismo que permite ao homem dotar-se de dignidade e tornar-se parte integrante dos rumos do desenvolvimento social e econômico do grupo ao qual se insere. É o trabalho que fundamenta a participação política e que confere ao homem o seu lugar no mundo.

Em outros termos, a perspectiva laboral dos direitos, decorre dos embates históricos da modernidade, os quais embora inseridos no espaço da cidadania social, com características próprias dos direitos humanos, são retirados da ideia e da ideologia de mercado, restando limitados na acepção de garantia dos direitos civis e políticos. A cidadania social acaba por não produzir os efeitos desejados quanto às demais acepções dos direitos humanos, permanecendo adstrita às "liberdades" meramente formais.

No sentido jurídico, o valor social do trabalho conforma em seu bojo o conjunto de atribuições que são eminentemente principiológicas. Desta feita, as mesmas funções que Luño (2005) apresenta para os direitos fundamentais, ao descrever o papel hermenêutico das dimensões da igualdade, cumprem também ao valor social do trabalho, por este constituir-se também na tríplice dimensão (1) fundamentadora, (2) orientadora e (3) crítica.

A partir da base apresentada por Luño, pode-se afirmar que a dimensão fundamentadora do valor social do trabalho estabelece-se a partir do plano constitucional, meramente pela sua previsão, uma vez que o conjunto de disposições e instituições que decorrem da necessidade de realização dos direitos sociais (e também civis) a partir do trabalho, acaba por determinar nesses valores, os fundamentos da República, o primado da ordem social e a condução da ordem econômica (todos centrados no trabalho).

No sentido orientador, o valor social do trabalho detém uma acepção que deve nortear a atuação das instituições público-jurídicas, estabelecendo metas implícitas e/ou expressas que tenham como objetivo culminar com a imperiosidade de realização do trabalho como instrumento de emancipação e cidadania. Dessa forma, qualquer ação contrária ao valor social do trabalho é ilegítima, uma vez que impede a realização dos valores que formatam a sua centralidade.

Em sua acepção crítica, o valor social do trabalho serve de critério para a avaliação e valoração normativa e jurisdicional de todas as normas do ordenamento, bem como das ações dos 
setores públicos ou da esfera privada que tencionem ou tendam a reduzir garantias que se originam do trabalho.

Decorre, pois, da fundamentalidade do próprio trabalho, que a ideia do valor social do trabalho não pode ser meramente figurativa na Constituição Federal de 1988. Pode-se justificar, então, que a evolução do Estado brasileiro, no contexto constitucional fundado a partir de 1988, determina um conjunto de ações do Poder Público que devem estar voltadas à administração e distribuição dos recursos sociais, de forma a contribuir para a garantia e realização do desenvolvimento.

O valor social do trabalho atua de maneira decisiva sobre os sentidos do trabalho e sobre a dignidade humana, pois condiciona e orienta, de modo positivo, a construção de um ideal de cidadania que coloca a participação dos processos sociais como parte essencial do desenvolvimento. A cidadania representa, então, um meio que possibilita obter o fim social primordial do trabalho e das relações sociais que é promoção da dignidade.

As ações e posicionamentos do Poder Público devem ser reforçados pelo valor social do trabalho, de modo que a Administração Pública seja compelida a atuar no sentido de promover o trabalho em seus mais diversos sentidos, especialmente no que se refere à participação cidadã. $\mathrm{O}$ valor social do trabalho deve ser a matiz que instiga o legislador a produzir leis que protejam o trabalhador e, em contraponto, impeça-o de reduzir ou limitar os direitos trabalhistas, bem como, sirva ainda de parâmetro para o Judiciário quando da sua atuação precípua de solver conflitos sociais que tenham o trabalho como objeto ou matriz.

\section{PROTEÇÃO E ACESSO AO TRABALHO: CONTEÚDO E DESAFIOS À EFETIVAÇÃO DO VALOR SOCIAL DO TRABALHO}

Quando se afirma o poder conformador decorrente das atribuições do valor social do trabalho, estabelece-se a necessidade de verificar e compreender quais as suas acepções normativas e, principalmente, o seu conteúdo. É a partir dessa compreensão que se pode definir os parâmetros que orientam o neoconstitucionalismo social brasileiro pautado no trabalho.

$\mathrm{O}$ valor social do trabalho acaba por garantir uma dupla acepção que fundamenta e determina a estruturação dos próprios sentidos do trabalho. Num primeiro momento se identifica o trabalho como atividade capaz de gerar um resultado útil ao homem e à sociedade, assumindo, pois, um caráter sociológico, fundado na precedência do trabalho à própria atividade social.

Essa ação - o trabalho - é inserida num contexto social do qual são extraídos os valores que promovem a circulação do capital e que, por sua vez, gera a mais-valia. Da interação humana, nos espaços políticos e sociais, além obviamente dos conflitos históricos em torno do exercício do trabalho, decorreu a sua normatividade e controle.

O trabalho passou a ser definido também pelos mecanimos de proteção ao seu exercício, cofundindo-se muitas vezes com o próprio direito do trabalho. Assim, acaba por inserir-se na esfera do conteúdo do valor social do trabalho, a ideia de proteção que é instrumentalizada pelo direito do trabalho, reconhecido como disciplina autônoma e detentora de princípios próprios.

Todavia, na esfera normativa, como se defende até aqui, o trabalho não pode ser considerado exclusivamente na sua acepção protetiva ou unicamente ligado ao direito do trabalho. Na realidade, valor social do trabalho desempenha uma dupla acepção que revela o seu conteúdo, como uma faceta clara do trabalho enquanto atividade e objeto da proteção jurídica.

Desta maneira, o valor social do trabalho, diante dos desafios que se colocam à sua efetivação, apenas pode tornar-se um instrumento normativo dotado de eficácia se no seu conteúdo forem reconhecidas as acepções de proteção e acesso. Na perspectiva da proteção, o valor social do trabalho é capaz de promover a proteção social do cidadão-trabalhador, instrumentalizada por mecanismos normativos da legislação e da atividade judicial que reconheçam, principalmente no direito do trabalho os limites à atividade laboral. 
Na perspectiva do acesso, o valor social do trabalho deve ser capaz de garantir, uma vez firmado o caráter dignificante do trabalho, a possibilidade de cada sujeito alcançar uma ocupação que lhe permita usufruir dos benefícios sociais e econômicos dele decorrentes, tais como o acesso à renda, à inclusão econômica, à inserção social e à dignidade pela autodeterminação enquanto sujeito produtivo. A acepção de acesso deve ser também o elemento determinante para o reconhecimento do direito ao trabalho, não apenas ligado à compreensão meramente formal da obrigação ao empregador de "dar trabalho" ao obreiro, mas numa acepção ampla ligada aos direitos humanos de dimensão solidária, que exige uma atuação positiva dos Estados e da própria sociedade de garantir inclusão social pelo trabalho.

Assim, o valor social do trabalho, além de uma categoria normativa, revela uma forte predisposição à sua concreção social e à transformação emancipatória. Ao admitir que o valor social do trabalho vá além de mera figuração decorativa no texto constitucional, possibilita-se que se deixe o plano da mera validade formal, passando-se a exigir atitudes concretas no plano da efetivação do direito ao trabalho.

O valor social do trabalho permite a fundamentação, a orientação e a crítica do plano da facticidade, tornando exigível o seu conteúdo. Embora de maneira ainda embrionária, no que se refere à proteção integral do valor social do trabalho, em decisão em sede de Recurso Ordinário no Tribunal Regional do Trabalho da $23^{a}$ Região, o ministro Édson Bueno se pronunciou:

[...] as relações de trabalho devem pautar-se pelo respeito mútuo ante o seu caráter sinalagmático. O empregador, além da obrigação de dar trabalho e de possibilitar ao empregado a execução normal da prestação de serviços, deve respeitar a honra, a reputação, a liberdade, a dignidade e a integridade física e moral dos seus empregados (MATO GROSSO, 2011).

O enunciado, embora apresente os pressupostos da ideia da ocupação do posto de trabalho, permite antever a conformação normativa do valor social do trabalho aqui proposta. Decorre do excerto, a ideia de que as relações de trabalho devem ser pautadas no respeito, conferindo, portanto, proteção ao trabalhador. Vislumbra-se ainda a obrigação de "dar trabalho", que decorre da condição de empregador, que o compele a fornecer, ao seu empregado, tanto o trabalho quanto as condições de concretizá-lo, em respeito às regras protetivas do direito do trabalho.

Evidentemente, a expressão "dar trabalho" não tem o mesmo sentido do acesso ao trabalho, indício claro de um verdadeiro direito humano fundamental ao trabalho. A dação de trabalho pelo empregador pressupõe a ocupação de um posto, o que ocorre a posteriori, como decorrência lógica de uma economia em que haja postos de trabalho que possam ser ocupados. É sob essa ótica que Wandelli (p. 400-401) argumenta que o direito ao trabalho:

[...] é um direito a que haja políticas que promovam o emprego em sentido pleno, ou seja, sob a forma juridicamente protegida do emprego como melhor patamar propiciado pela sociedade capitalista ao trabalho. Mas também, trata-se de um direito ao trabalho em um sentido muito anterior e mais amplo que o de alguma das formas de trabalho sob o capital. O direito a uma sociedade em que haja a efetiva possibilidade de obter com autonomia, pelas próprias capacidades, a reprodução e desenvolvimento da vida, o que inclui, também, essencialmente, o direito à possibilidade de alternativas de vida que não se subordinem às formas capitalistas de trabalhar.

Na prática, no Brasil, o direito ao trabalho, de nenhuma forma chama o empresariado a promover o acesso ao trabalho. Embora se reconheça o acesso ao trabalho como uma obrigação do Estado, nem ele é exortado realmente a fazê-lo. O direito ao trabalho, 
[...] cuida-se de um direito à possibilidade de vida pelo trabalho. É, nesse sentido, um direito que interpela, desde as necessidades dos sujeitos, pela dimensão radical do trabalho como necessidade humana, toda a ordem societária vigente, impulsionando não só ao contínuo aprimoramento de suas instituições, mas também à sua profunda transformação (WANDELLI, p. 399).

Desse modo, exige-se da conformação constitucional que os princípios da proteção social e do acesso ao trabalho, que compõem e formam a essencialidade e o conteúdo do valor social do trabalho, apregoados na Constituição Federal de 1988, sejam dotados de efetividade. O valor social do trabalho não importa somente na criação de elementos jurídicos de proteção ao trabalhador, inseridos na legislação trabalhista, mas garante também que a ideia de igualdade material seja tornada eficaz.

Normativamente, o princípio do acesso ao trabalho foi mencionado pela primeira vez em 1848, quando da proclamação da segunda República Francesa, ao criar as oficinas nacionais para proporcionar trabalho para os desempregados, tendo sido retomado posteriormente na Constituição de 1946 e na atual constituição francesa (VIE PUBLIQUE, 2013).

Mais recentemente, pode-se apontar a Resolução n. ${ }^{\circ}$ 34/46, de 1979, da Assembleia Geral da Organização das Nações Unidas (ONU), que enuncia: "[...] a fim de garantir cabalmente os direitos humanos e a plena dignidade pessoal, é necessário garantir o direito ao trabalho". Ou seja, o "não acesso ao trabalho" é também o "não acesso aos direitos humanos como um todo", o que impede o acesso isonômico aos direitos humanos.

No texto constitucional, o princípio da isonomia não está, de modo algum, entrincheirando os sujeitos sociais, um em face do outro, como se fossem sujeitos padronizados e imunes à realidade. Ao contrário, o princípio da igualdade tem como condão de promover a justiça no Estado Democrático de Direito, indo além do seu aspecto eminentemente formal.

Como consectário do Estado Social, o Estado Democrático de Direito constituído no Brasil, comum também na maioria dos países ocidentais, objetiva a proteção do hipossuficiente, para que efetivamente se tenha uma igualdade efetiva, capaz de assegurar dignidade a todos. Dessa forma, o princípio da proteção, no modelo econômico capitalista, serve para garantir mecanismos mínimos para que se possam resguardar direitos aos mais necessitados. Assim, nas palavras de Castel (2008, p. 19), os indivíduos, para quem é destinada a proteção social, são aqueles que "[...] vivem sob o signo da ameaça permanente porque não possuem em si mesmo o poder de proteger e de proteger-se"

No avanço do reconhecimento do trabalho como principal agente de transformação econômica e de inserção social, não se pode admitir que aqueles mais fracos sejam deixados à própria sorte diante de uma massa feroz e autofágica que é o capital. As normas de proteção ao trabalhador dizem respeito a diversas das condições laborais, podendo-se afirmar, contudo, que a jornada e o salário são objeto de especial proteção.

A insegurança social gera a necessidade de meios de proteção social para os membros da sociedade moderna, as quais são vinculadas aos mecanismos de proteção e aos direitos relacionados às condições dos próprios trabalhadores (CASTEL, 2008, p. 41). Nessa medida, o trabalho deixa de ser encarado exclusivamente como uma relação de mercado, no marco de uma relação contratual e econômica, para se tornar um sistema de proteção cujo contexto político determina a maior parte dos avanços sociais.

Essa plataforma de proteção sofre, a cada dia, golpes do capital, o qual tenta promover uma aniquilação da força mobilizadora do trabalho, reduzindo-o a mera mercadoria. Como bem lembra Cecato (2012, p. 27), a negação do trabalho, ou a desproteção do trabalhador constitui em negação ao próprio sujeito de participar das dimensões do desenvolvimento.

2 Tradução do autor. No original: “[...] viven bajo el signo de la amenaza permanente porque no poseen em sí mismos el poder de proteger y de protegerse".

Revista de Direito Brasileira | São Paulo, SP | v. 16 | n. 7 | p. 115 - 134 | Jan./Abr. 2017 
A negação do trabalho ao sujeito que compõe a "classe-que-tem-condições-de-viver-dotrabalho ${ }^{3 "}$ além de lhe impossibilitar acesso ao ganho material, que lhe é indispensável, o afasta também da sua vida social, política e cultural, que restam comprometidas. O sujeito perde a sua identidade e a capacidade de ser um cidadão pleno e solidário, dotado de dignidade.

Cabe esclarecer que qualquer alteração que vise prejudicar a classe trabalhadora, seja pela via infraconstitucional ou mesmo através de Emenda à Constituição, fere o princípio da proibição de não retrocesso social, sendo, portanto, inconstitucional, e agride a acepção protetiva do valor social do trabalho.

O princípio da proteção é corolário ainda da democracia econômica e social que além de apontar para a proibição do retrocesso social exige que sejam adotadas medidas positivas (ações afirmativas) no sentido da promoção do sujeito trabalhador. Castelo, nesse particular, reforça a ideia do princípio da proibição de retrocesso social ao lembrar:

Na verdade, o caput do art. $7^{\circ}$ da $\mathrm{CF}$ ao estabelecer que "são direitos dos trabalhadores urbanos e rurais, além de outros que visem à melhoria da sua condição social" fixa dois princípios fundamentais do direito do trabalho. Primeiro, estabelece como objetivo do direito laboral a melhoria da condição social, e com isso fixa a proibição de retrocesso social por norma infraconstitucional. Segundo, eleva ao plano constitucional a garantia da norma mais favorável (CASTELO, 2007, p. 95-96).

Ainda decorrem do princípio da proteção social, na esfera da relação empregatícia, os subprincípios da norma mais favorável e da condição mais benéfica que pressupõem, respectivamente, normas com vigência simultânea, impondo que seja escolhida aquela que promova uma interpretação mais condizente com a melhoria da condição social do trabalhador ${ }^{4}$. É o que preconiza Oliveira (2001, p. 243) ao afirmar que “[...] em qualquer confronto que existir concretamente na aplicação de determinada norma jurídica, a proteção do trabalhador deverá sair sempre vitoriosa, enquanto bem jurídico fundamental".

O valor social do trabalho, de claro fulcro constitucional, é a raiz do princípio da proteção social, através do qual se reconhece e se exige que a "vontade da constituição" prevaleça (HESSE, 1991). Conquanto se admita a proteção social, como elemento de garantia da estabilização da condição do trabalhador, não se pode olvidar que o contexto hodierno de globalização flexibilizatória e precarizante tende a corroer os elementos mais essências à realização da "classe-que-tem-condições-de-viver-do-trabalho".

O padrão de proteção referido, no contexto da globalização, conta, em grande parte, com a ação normativa da OIT, através das Convenções e mesmo das Declarações aprovadas, no intuito de promover a normatividade do valor social do trabalho. Há de se apontar que muitas das conquistas sociais protetivas atuais foram, na verdade, asseguradas como concessões, mais garantidoras dos interesses dos donos do capital do que propriamente do trabalhador.

Essas "concessões" do capital, embora funcionem como uma prática conservadora, ainda assim não são ilegítimas, uma vez que promovem, a contragosto do próprio capital,

\footnotetext{
3 A partir da expressão "classe-que-vive-do-trabalho" de Ricardo Antunes (2007, 2007a) e utilizando-a como mote, cunhou-se a expressão "classe-que-tem-condições-de-viver-do-trabalho" que abarca, dentro da categoria dos desempregados, que compõem o exército de reserva, aqueles que não estão apenas desempregados, mas são excluídos completamente do mercado formal de trabalho e sobrevive, não raras vezes, porque percebe, da assistência social um benefício pecuniário de inserção socioeconômica (ARAÚJO, 2016).

4 Delgado (2007) apresenta ainda os seguintes princípios do direito do trabalho: princípio da imperatividade das normas trabalhistas, princípio da indisponibilidade dos direitos trabalhistas, princípio da inalterabilidade contratual lesiva ou intangibilidade contratual objetiva, princípio da intangibilidade salarial, princípio da primazia da realidade sobre a forma, princípio da continuidade da relação de emprego, princípio in dubio pro operario, princípio do maior rendimento. É clara a correlação lógica e jurídica de todos esses princípios com o princípio laboral nuclear da proteção social.
}

Revista de Direito Brasileira | São Paulo, SP | v. 16 | n. 7 | p. 115 - 134 | Jan./Abr. 2017 
melhorias à vida dos cidadãos. O grande peso social para a normatividade do valor social do trabalho é que são essas mesmas concessões as primeiras a sofrerem o ataque das ondas flexibilizatórias e precarizantes. Como afirma Vilhena (2014, p. 290):

Tal importância se mostra tão evidente que os que postulam a flexibilização tendem a atacar o princípio da proteção contundentemente, pois, com o enfraquecimento das normas tendentes a minimizar as desigualdades inerentes à relação de emprego, fatalmente trará como consequência direta à morbidade do Direito do Trabalho e o fortalecimento dos mais fortes em detrimento dos mais fracos. A estratégia da busca da flexibilização da legislação trabalhista mediante o enfraquecimento do princípio da proteção já vem sendo adotado em diversos países do mundo.

É por essa razão que a eliminação do postulado da proteção é campo de batalha das forças do capital. Em vistas disso, como decorrência do próprio contexto capitalista, o princípio da proteção tem o seu papel ampliado, reforçando a importância dessas conquistas.

O capital é apresentado como uma pressuposição externa que contrapõe o capitalista e o trabalhador em uma situação de aparente igualdade, entretanto, o aprofundamento das relações econômicas revela a real condição de ambos os polos dessa relação socioeconômica. As reflexões acerca do princípio da proteção, portanto, são confirmadas, uma vez que a simples aparência de igualdade faz caírem por terra as justificativas do capital, no sentido de que deve imperar a igualdade formal.

A apropriação da riqueza pelos donos do capital, não pelo trabalho próprio, mas pela exploração do trabalho alheio, estabelece um parâmetro de desigualdade que seria impossível de ser superado com a abstenção legal. E é sob o argumento da não regulamentação que o capital tem conseguido produzir e manter em estado de miséria três quartos da população mundial. Como bem observa Deleuze (1992, p. 224-225) “[...] pobres demais para a dívida, numerosos demais para o confinamento: o controle não só terá que enfrentar a dissipação das fronteiras, mas também a explosão de guetos e favelas".

Como argumento para a supressão do cunho protetivo do valor social do trabalho, Romita (2003, p. 23) expõe que para o capital:

[...] Não é função do direito do trabalho proteger o empregado. Função do direito do trabalho é regular as relações entre empregado e empregador, tout court. Afirmar a priori a função protecionista do direito do trabalho em benefício do empregado desconhece a bilateralidade da relação de emprego. Aceito o caráter sinalagmático do contrato de trabalho, seria de rigor a aceitação de igual dose de proteção concedida ao empregador: o instituto da falta grave e a repressão à greve podem ser lembrados como exemplos.

Não se pode admitir o argumento de que o princípio da proteção vai de encontro ao ideal de Democracia. Ao contrário, reconhecer a desigualdade a priori dos sujeitos sociais é aplicar sistematicamente a Constituição Federal que apresenta como objetivo da República a redução das desigualdades regionais e sociais, fator democrático e inclusivo que considera a hipossuficiência do trabalhador.

A não incidência do princípio da proteção deve ser veementemente afastada, sob pena de se colocar em xeque a própria existência do neoconstitucionalismo social que se funda na centralidade dos direitos sociais. No sentido oposto, o princípio da proteção deve ser ampliado, estendido para além das fronteiras do direito do trabalho, alcançando as relações sociais decorrentes da atuação estatal, quando da implementação social nas mais variadas esferas dos direitos sociais. 
O princípio da proteção deve ser o fundamento de políticas públicas do Estado brasileiro que sejam condizentes com os valores constitucionais e com os ideais de dignidade humana, de existência digna e de justiça social, de modo a se garantir cidadania a todos os sujeitos sociais. Pode-se então afirmar com certa tranquilidade que a proteção social não se dirige unicamente ao trabalhador, embora seja o trabalhador um de seus beneficiários mais presentes.

Com o reconhecimento da relevância normativa do valor social do trabalho abre-se caminho para o enfrentamento dos infortúnios e riscos, no sentido da melhoria das condições de saúde e de subsistência das pessoas, o que também deixa ainda mais clara a expansão do valor social do trabalho para a ideia de acesso às oportunidades de trabalho e para a inclusão social. $\mathrm{O}$ que por conseguinte também se estende para o exercício da cidadania.

Compreendendo a acepção de "proteção do trabalho", como pressuposto de uma sociedade do trabalho, é que é possível se considerar que também o "acesso ao trabalho" é o outro elemento informador, contido no "princípio do valor social do trabalho".

Não se pode falar em valor social do trabalho se não há trabalho. É o acesso ao trabalho que permite que o cidadão seja reconhecido como trabalhador e possa, então, usufruir da proteção estatal e dos benefícios decorrentes do desenvolvimento. Para Castel (1995, p. 387), "o trabalho é mais do que o trabalho [...] e, portanto, o não trabalho é mais do que desemprego".

Essa reflexão remete ao papel integrador desempenhado pelo trabalho na sociedade de ideologia capitalista, para se compreender que "[...] a característica mais perturbadora da situação atual é sem dúvida o reaparecimento de um perfil de trabalhadores sem trabalho, os quais ocupam literalmente na sociedade um lugar de excedente, de inúteis no mundo (CASTEL, 1995, p. 399)”. Isso representa a ausência de dignidade quando da ausência de trabalho.

O valor social do trabalho, ao irradiar seus efeitos, determina que além da proteção aos já inseridos socioeconomicamente (proteção) seja possibilitada a manutenção dos postos de trabalho, como também seja disponibilizado acesso ao trabalho àqueles que não o possuem (acesso). Desse modo, tanto o acesso ao trabalho como a manutenção do trabalho são perspectivas de uma mesma faceta do valor social do trabalho, constitucionalmente assegurados.

Marques (2008, p. 65), reflete que ao Estado cabe a promoção do acesso ao trabalho, como corolário de um direito ao trabalho:

O direito ao trabalho envolve o direito ao acesso e manutenção de uma ocupação produtiva, o que confere uma dimensão promocional à atividade do Estado, mas não atribui aos indivíduos um instrumento judicial específico para assegurá-lo. Nos termos da compreensão prevalecente na atualidade, na doutrina e jurisprudência trabalhista pátrias, embora o direito ao trabalho possa ser invocado, por exemplo, para impedir praticas discriminatórias no acesso ao emprego, não há obrigação legal de que um particular ou o Estado ofereça um posto de trabalho a um determinado indivíduo, apenas em razão do reconhecimento do direito ao trabalho.

Muito embora se assevere, acerca da obrigação do Estado de promover o acesso ao trabalho, que esse não é um dever que exige o cumprimento do seu resultado - ou seja, não se configura como uma obrigação absoluta para dar a cada pessoa desempregada um emprego -, essa obrigação se constitui no dever de se envidar esforços para que sejam implementadas políticas que permitam a todos conseguir um emprego.

O valor social do trabalho informa o norte positivo que deve ser seguido a partir da ideia de prestações do Estado. No entanto, as formas de se impedir a plenitude do valor social do trabalho são cada vez mais difusas e eficazes em obstar a sua eficácia. Nesse sentido, ferindo o princípio constitucional do valor social do trabalho, na acepção de acesso, o Estado brasileiro denunciou a Convenção no 158 da OIT que trata do "Término da Relação de Trabalho por Iniciativa do Empregador". 
A Convenção 158 da OIT, foi aprovada pelo Estado brasileiro pelo Decreto Legislativo $\mathrm{n}^{\mathrm{o}}$. 68, de 16.09.1992, do Congresso Nacional, tendo sido ratificada em 05 de janeiro de 1995, e sua promulgação se deu pelo Decreto $\mathrm{n}^{\circ}$. 1.855, em 10.04.1996, tendo sido unilateralmente denunciada em ato do então Presidente da República Fernando Henrique Cardoso pelo Decreto $n^{\circ}$. 2.100, em de 20.12.1996 .

A convenção protegia o trabalhador do término abrupto da relação laboral, condicionando a extinção do contrato de trabalho à existência de justa causa devidamente justificada "relacionada com sua capacidade ou seu comportamento ou baseada nas necessidades de funcionamento da empresa, estabelecimento ou serviço". Como garantia de efetivação do direito ao trabalho, a convenção determinava que antes de qualquer situação que pudesse ocasionar o término da relação laboral fosse concedida oportunidade de defesa ao trabalhador, bem como se lhe garantisse a possibilidade de recorrer a um órgão imparcial. Garantiam-se ainda direitos como aviso prévio, benefícios previdenciários de seguro desemprego, além de eventuais indenizações.

A denúncia à Convenção revela a dificuldade de se compreender a efetividade normativa que deve ser conferida ao valor social do trabalho no contexto socioeconômico brasileiro, na sua acepção do "acesso ao trabalho". Ainda são milhões os cidadãos que embora em idade economicamente ativa, não estão inseridos no mercado de trabalho e não são, por sua vez, reconhecidos pela sua dignidade como integrantes do processo de desenvolvimento.

Os direitos sociais que advém do valor social do trabalho, em especial na sua perspectiva de acesso, exigem que prestações positivas sejam desenvolvidas para o pleno desenvolvimento da existência individual cidadã. Esses direitos têm como sujeito passivo o Estado que deve cumprilos com a definição e execução de políticas públicas que fomentem o acesso a oportunidade laborais que permitam a inserção social. São ações solidárias que deve se tornar exigíveis, não exclusivamente contra o Estado, mas, principalmente, através do Estado.

Na mesma perspectiva, os arranjos produtivos locais (APLs) têm se mostrado elemento essencial para garantir a realização do ideal de acesso ao trabalho. Carneiro (2004) define os arranjos produtivos locais como:

[...] aglomerações de empresas e/ou produtores localizados em um mesmo território, que apresentam especialização produtiva e mantêm algum vínculo de articulação, integração, cooperação e aprendizagem entre si e outros atores locais, tais como: governo, associações empresariais, instituições de crédito, ensino e pesquisa.

Os arranjos produtivos são uma possibilidade mais ampla de se gerar trabalho e conferir eficácia à acepção de acesso do valor social do trabalho. A alteração das prioridades na gestão das organizações sociais e estatais tem referenciado a reestruturação das ações públicas e privadas em função da promoção do desenvolvimento como política pública a ser adotada pelo Estado brasileiro em todas as searas produtivas. Esta foi também a forma de interpretação da perspectiva do acesso ao trabalho dada pelo Conselho Constitucional Francês.

Em decisão de 1983, o Conselho afirmou que ao legislativo cabe a proposição de regras para melhor assegurar o direito de toda pessoa a conseguir um emprego, a fim de permitir o exercício deste direito para o maior número de interessados. Foi nesse contexto que foi criado na França, em 1967, a Agência Nacional de Emprego (ANPE) no intuito de promover ações que viabilizassem o acesso ao emprego na França (VIE PUBLIQUE, 2013).

5 O decreto de Denúncia foi objeto de Ação Direta de Inconstitucionalidade (ADI 1.625/DF), cuja tramitação esteve parada durante quase 20 anos, até o ano de 2016, quando o julgamento foi retomado, embora ainda permaneça sem decisão. 
O acesso ao trabalho contribui para a dignidade do ser humano, sendo um instrumento de garantia de realização das promessas públicas de desenvolvimento e de promoção da cidadania. Entretanto, o seu âmbito normativo, como direito, ainda permanece muito restrito, uma vez que, em razão das dificuldades econômicas enfrentadas na economia mundial e nacional, a sua eficácia continua restrita e a compreensão amplamente difundida é de que não é possível a sua sindicabilidade judicial.

É imperioso que essa consideração acerca da não sindicabilidade do direito ao trabalho seja repensada, uma vez que deve ser cumprido o papel constitucional do Estado Democrático de Direito brasileiro de promover políticas públicas de trabalho e emprego eficazes e condizentes com os valores contidos no texto constitucional.

A esse respeito, pode-se asseverar que, em consonância com as palavras de Albornoz $(1989$, p. 24) a "[...] possibilidade de uma sociedade de trabalhadores sem trabalho não aparece como uma libertação do mundo da necessidade, mas como uma ameaça inquietante". Ao contrário, não se coloca em prática o princípio do valor social do trabalho e, a cada dia, mais ações conservadoras são adotadas, atacando e pondo à prova "o acesso ao trabalho" como uma das acepções do valor social do trabalho.

No Brasil, no contexto atual de reorganização econômica, são adotadas pelo Executivo e pelo Legislativo medidas anti-trabalho no sentido de se reduzirem as garantias existentes e asseguradas pela Constituição, historicamente, conquistadas pelas lutas sociais. São adotadas cada vez mais medidas no sentido da precarização dos direitos laborais, atacando o núcleo do valor social do trabalho, em suas duas acepções de proteção e acesso.

Neste sentido são, por exemplo, as propostas de regulamentação da terceirização, ampliando a sua abrangência para as chamadas atividades-fim, o ajuste fiscal com o aumento das exigências para se acessar o seguro desemprego, entre outras medidas de ajuste socioeconômica que acabam atacando e precarizando ainda mais a condição de trabalhador, além da PEC 241, que visa estabelecer um ajuste fiscal que limita os gastos públicos com diversos direitos sociais pelo prazo de 20 anos.

\section{PRECARIZAÇÃO COMO CONTRAPONTO FÁTICO À REALIZAÇÃO DO VALOR SOCIAL DO TRABALHO}

É evidente que ao se referir aos avanços sociais decorrentes da globalização, não se pode deixar de lado o contexto no qual os Estados, em especial o brasileiro, estão inseridos. O valor social do trabalho é o norte que fundamenta, como se tem afirmado, a proteção social e a disponibilização de acesso e a manutenção de postos e vagas de trabalho e emprego.

Como se pode depreender da realidade, os avanços globais relativos às novas invenções e ao acesso às novas tecnologias têm sido inseridos diuturnamente no mundo do trabalho. Essas inovações apresentam-se, inclusive, como um marco socioeconômico importante no que se refere ao aumento da produtividade e à ampliação dos lucros, entretanto, para o cidadão-trabalhador essas transformações tecnológicas não têm sido positivas.

Materialmente, ou economicamente, até seria possível, com a ampliação dos recursos econômicos no mundo, desde o marco histórico da globalização, avanços quanto ao combate à miséria, a saúde e a justiça social, no entanto, esses avanços não foram disponibilizados aos cidadãos.

A tentativa de retirada da centralidade do trabalho tem sido relacionada à desestabilização geral da condição salarial, com a fragilização da mão-de-obra assalariada, com a precarização e a flexibilização de modo a modificar profundamente os valores sociais. É por essa razão que é preciso considerar não apenas o desemprego como ameaça ao trabalho, mas também a degradação da condição do trabalhador, o que acaba por alimentar o número de excluídos como resultado de um processo de redução de direitos sociais. 
Em razão dessas circunstâncias, a solidariedade deve ser levada em conta de modo a não ser sufocada pelas pressões políticas e econômicas que acabam por atingir o primado do trabalho. Como aponta Delgado (2007, p. 11), o primado do trabalho e do emprego constitui uma das maiores conquistas da democracia no mundo moderno. A esse respeito, Cecato (2007, p. 356) assere ainda que:

Construído na primeira metade do século XX, o primado do trabalho vem sendo, nas últimas décadas, atingido, em sua estrutura e em seus princípios, por fatores que se condensam no contexto da intensa, rápida e ávida evolução do capitalismo. A intensificação da globalização econômica, permitida por novas técnicas de comunicação e produção, assim como a reorganização racional das empresas, na busca por melhor inserção no mercado, fazem crescer as pressões pela flexibilização das normas laborais e das condições de trabalho. Esta se faz segundo a ótica da ideologia (neo)liberal de acomodação dos direitos trabalhistas aos interesses do empresário - empregador.

Como se vê, na contramão do pensamento social proposto no texto da Constituição Federal de 1988, há uma inegável tentativa de promover a sua desconstrução no sistema capitalista, tudo a pretex to da globalização. A ideologia neoliberal está assentada na ideia de que o crescimento e o desenvolvimento dependem da competitividade do mercado, com o intuito de ampliar a concorrência, aumentando a flexibilidade do trabalho e a transferência dos riscos sociais e da insegurança econômica para o trabalhador.

As transformações sociais aprofundadas pelo processo de mundialização e de avanço tecnológico têm trazido graves problemas sociais quanto ao nível de emprego e à garantia dos direitos sociais conquistados pelos trabalhadores. Ramalho e Santana (2010, p. 8-9) observam que ao mesmo tempo em que os índices de desemprego se tornam elevados em muitos países do mundo, incluindo as economias centrais, há paralela aplicação de uma política de desmantelamento da ação do Estado nas áreas sociais, o que nos países subdesenvolvidos leva ao recrudescimento dos níveis de desemprego e o número de pessoas na informalidade.

Como bem lembra Druck (2013, p. 65), são considerados trabalhadores informais aqueles assalariados sem carteira de trabalho, que não sabem definir sua condição de trabalho, sejam autônomos, empregadores que não recolhem a contribuição social para a Previdência, empregadas domésticas sem carteira, trabalho familiar, dono de negócio familiar, dentre inúmeros outros. E a informalidade é também, por suas características de redução de direitos, um elemento de desvalorização ao trabalho.

Por seu turno, Roesler (2014, p. 45) afirma que o trabalho humano passa a ser desvalorizado tanto na sua esfera econômica, representando um peso econômico e fiscal aos orçamentos públicos e das empresas, quanto social gerando demandas sociais por mais benefícios sociais, para os quais os representantes do governo e dos próprios trabalhadores passam a defender a redução dos direitos trabalhistas como forma de baratear os seus produtos, fazendo com que possam ser inseridos no mercado de trabalho "em crise". Ou seja, a grande massa de excluídos pela flexibilização - que já ocorre - estaria disposta a aceitar ainda mais ataques à proteção do trabalho em troca a integrar o mercado oficial, isto porque "[...] em nome da governabilidade e da empregabilidade tudo se permite, até mesmo a usurpação dos direitos dos trabalhadores (GONÇALVES, 2004, p. 105)".

Seria, portanto, fundamento para a precarização, a ideia de que a grande massa de excluídos do mercado formal passaria a integrar o mercado oficial de trabalho tendo mais acesso a direitos mínimos que lhes garantiria dignidade. Entretanto, na realidade o que ocorre é o contrário. $\mathrm{O}$ mercado tem condições de suportar os encargos decorrentes do trabalho. $\mathrm{O}$ que não se quer perder é a ampliação dos lucros, a pretexto de se reduzir direitos para ampliar postos de trabalho. Há evidentemente uma desvalorização do trabalho. 
A desvalorização do trabalho serve de pretexto para a adoção de medidas que tendem a atacar o núcleo do direito do trabalho que expressam a relevância da feição protetiva do seu valor social. A verdade é que o modo de produção capitalista e o argumento falho de que a precarização promoverá um ajuste fiscal capaz de ampliar os postos de trabalho não passa de uma falácia.

O verdadeiro mal-estar social, causado pela globalização, enquanto decorrência da ordem capitalista, é a desestruturação do mercado de trabalho. O modo de produção capitalista, gestado no mercado e na precarização, falha na tarefa de gerar emprego e renda, agudizando desigualdades regionais e sociais.

Sem dúvidas, o desemprego massivo alimenta a sensação de perda de identidade dos sujeitos sociais e ainda fortalece as incertezas acerca do futuro. Falham, simultaneamente, as instituições que tornam possível o vínculo social (especialmente, na iminência da crise do Estado Social), o vínculo social e a solidariedade (vislumbrada na crise do trabalho) e os modos de constituição das identidades individuais e coletivas (a crise do sujeito).

O direito ao trabalho é o epicentro de um conjunto de lutas pela sua realização. Para que seja possível a efetividade do direito ao trabalho, como face do valor social do trabalho não se pode admitir que o trabalho seja reduzido a uma mercadoria inserta no mercado estranhado e fetichizado. A ideia de estranhamento e de fetichização do trabalho deve ser radicalmente eliminada a partir da atuação estatal no sentido de proteção do trabalhador.

A proteção e o acesso ao trabalho, como decorrentes lógicos do valor social do trabalho, devem permanecer afastados do processo de desconstrução social do trabalho intentado pela globalização neoliberal que tem significado "[...] uma desefetivação, desrealização e brutalização ainda maiores do que aquelas já vivenciadas pela classe-que-vive-do-trabalho (ANTUNES, 2007, p. 177-178)".

Deve-se reconhecer, pois, a materialidade da Constituição de 1988, na perspectiva em que a globalização se revela como a antítese dos valores sociais nela afirmados. Os "avanços da globalização" que são tendencialmente levadas a cabo pelos governos e pelo mercado - políticas neoliberais, desregulamentação, flexibilização etc. - devem ser conformadas ou suprimidas em nome dos direitos fundamentais e do princípio da proibição de retrocesso social.

O direcionamento de ações e políticas públicas cujo fundamento seja o núcleo constitucional dos direitos sociais deve ser a base para a consecução e realização do projeto constitucional de desenvolvimento. É nesse contexto, que o valor social do trabalho foi erigido pelo constituinte de 1988 como fundamento da República. É evidente que tais ataques diretos se põem em decorrência do papel primordial que o trabalho desempenha nas lutas por melhorias nas condições de vida dos cidadãos, tendo sido historicamente a seara das mais árduas lutas e das mais gloriosas vitórias.

$\mathrm{O}$ amadurecimento das reivindicações sociais tem proporcionado gradualmente a consolidação do direito ao trabalho como um standard positivado de proteção aos cidadãos em meio à intensificação da onda da globalização, ainda que tenha se tornado trincheira atacada de todos os lados e de todos os modos (isso se comprova com o intento precarizante de levantes flexibilizatórios e de redução das garantias sociais dos trabalhadores).

Nesse contexto, o direito do trabalho foi estabelecido como estuário de institutos, princípios e regras jurídicas primordiais para o equilíbrio das relações de emprego, mas também das conquistas sociais que foram espraiadas para todos os cidadãos, principalmente com o desenvolvimento da constitucionalização dos direitos sociais no século XX, iniciada com a Constituição do México, de 1917, e com a Constituição da República de Weimar, de 1919.

Desse modo, devem ser inseridos mecanismos que garantam acesso e proporcionem a proteção social do trabalho e dos trabalhadores, conferindo dignidade na relação de trabalho, com o objetivo de promover uma conformação mais sólida das formas de proteção social ao valor social do trabalho, para além da proteção laboral. Considerando-se o contexto social marcado por 
uma economia cada vez mais fragmentada, essa previsão protetiva deve ter como base sólida o princípio da dignidade da pessoa humana, inserido como núcleo da proteção constitucional conferida aos cidadãos brasileiros.

\section{CONCLUSÃO}

Do trabalho decorre o valor humano que fomenta e preserva a dignidade. Essa apreensão do trabalho como fundamento político conformador e ético importa em conferir ao trabalho e a seus agentes (tanto trabalhadores, quanto os que têm condições de trabalhar, mas estão fora do mercado de trabalho) tratamento protetivo e racionalmente condizente com a mens constitucional.

O trabalho e o seu valor consubstanciam cláusulas principiológicas que, estabelecem, pelo seu conteúdo, a necessidade de conformação de uma realidade de exploração capitalista, a partir de seu potencial transformador. O texto constitucional, por sua vez, estabeleceu o elo entre o princípio fundamental do valor social da livre iniciativa e o princípio fundamental do valor social do trabalho, atrelando-os lado a lado como fundamentos da República.

Valorizar o trabalho significa proporcionar, a partir da atividade laboral, não apenas à construção de uma ideia de bem-estar social, mas proporcionar alívio das condições subumanas impostas a milhares de pessoas. As melhorias à vida dos trabalhadores se espraiam por toda a vida social, especialmente daqueles que se encontram em condição de pobreza.

A acepção protetiva do valor social do trabalho é a base sólida de efetivação da dignidade da pessoa humana, como decorrência lógica do núcleo da proteção constitucional conferida aos cidadãos brasileiros face o contexto social marcado por uma economia cada vez mais fragmentada e mergulhada em uma profunda crise.

Dito isto, o trabalho passa a ser compreendido como um processo ativo de percepção da própria dignidade humana. É obvio que para a manifestação plena da dignidade, o trabalho deve ser encarado com equilíbrio ante a ideia da livre iniciativa do capital, de modo que se conciliem os interesses dos trabalhadores, com os interesses do capitalismo. Mencionado equilíbrio não é fácil, uma vez que a força do capital financeiro pressiona os trabalhadores, gerando tensão e embates sociais.

Como se percebe, a materialidade principiológica da Constituição de 1988 é pautada na cidadania, na sua perspectiva social. Dessa forma, a globalização no seu modelo neoliberal revela-se como antítese aos valores sociais nela afirmados, especialmente o trabalho. Os mencionados avanços da globalização acabam sendo direcionados para políticas neoliberais, desregulamentação e flexibilização, as quais - em sendo considerado o valor trabalho e o fim social orientado para o bem-estar - devem ser suprimidas em nome dos direitos fundamentais e do princípio da proibição de retrocesso social. É nesse contexto, que o valor social do trabalho é erigido pelo constituinte de 1988 como fundamento da República.

Assim, é evidente que os ataques neoliberais diretos ao valor trabalho devem ser superados. Em sentido oposto, devem ser implementadas ações e políticas públicas com o fundamento de promover a dignidade e a cidadania social, alicerçadas no núcleo constitucional dos direitos sociais e voltadas para a consecução e realização do projeto constitucional de desenvolvimento.

O valor social do trabalho, apresentado como elemento que garante a proteção e o acesso do trabalhador aos postos de trabalho, no contexto de uma economia submetida à intervenção do Estado Democrático de Direito, cujo escopo é manter o respeito ao ser humano como fim primordial de suas ações. Desse modo, devem ser inseridos mecanismos que garantam acesso e proporcionem a proteção social do trabalho e dos trabalhadores, conferindo dignidade na relação de trabalho, com o objetivo de promover uma conformação mais sólida das formas de proteção social ao valor social do trabalho, para além da esfera do direito do trabalho. 


\section{REFERÊNCIAS}

ALBORNOZ, S. O que é trabalho. Col. Primeiros Passos, 171, 3. ed. São Paulo: Brasiliense, 1989.

ANTUNES, R. Adeus ao trabalho? Ensaio sobre as metamorfoses e a centralidade do mundo do trabalho. 12. ed. São Paulo: Cortez; Campinas: Universidade Estadual de Campinas, 2007.

Sentidos do trabalho: ensaio sobre a afirmação e a negação do trabalho. São Paulo: Boitempo, 2009.

ARAÚJO, J. M. Função emancipadora das políticas sociais do Estado brasileiro: conformação das ações assistenciais do Bolsa Família ao valor social do trabalho. 400f. Tese (Doutorado em Ciências Jurídicas), Universidade Federal da Paraíba, Centro de Ciências Jurídicas, João Pessoa, 2016.

ARENDT, H. A condição humana. 2. ed. Trad. Roberto Raposo. Rio de Janeiro: Forense Universitária. 1983.

BELTRAN, A. P. Os Impactos da Integração Econômica no Direito do Trabalho: globalização e direitos sociais. São Paulo: LTr, 1998.

BOCORNY, L. R. A valorização do trabalho humano no Estado Democrático de Direito. Porto Alegre: SAFE, 2003.

BRITO FILHO, J. C. M. Trabalho decente: análise jurídica da exploração do trabalho: trabalho forçado e outras formas de trabalho indigno. São Paulo: LTr, 2004.p.126.

CANOTILHO, J. J. G. O Direito Constitucional na Encruzilhada do Milênio. De uma disciplina dirigente a uma disciplina dirigida. In: Constitución y Constitucionalismo Hoy. Caracas: Fundación Manuel García-Pelayo, 2000, p. 217-225.

CARNEIRO, F. Estado de Alagoas ganhará dez novos arranjos produtivos locais, SEBRAE, 31 ago., 2004. Disponível em: <http://www.al.agenciasebrae.com.br/sites/asn/uf/AL/Estado-deAlagoas-ganhar\%C3\%A1-dez-novos-arranjos-produtivos>. Acesso em: 30 dez. 2015.

CASTEL, R. Les metamorphoses de la question sociale: une choronique du salariat. Paris: Fayard, 1995.

La inseguridad social: qué es estar protegido? 1. ed. 2. reimp. Buenos Aires:

Manantial, 2008. 
CASTELO, J. P. A norma do direito do trabalho. Os fundamentos do direito do trabalho. In: CORREIA, Marcus Orione Gonçalves (org.). Curso de Direito do Trabalho. 1. vol. Teoria Geral do Direito do Trabalho. São Paulo: LTr, 2007, p. 85-98.

CECATO, M. A. B. Direitos humanos do trabalhador: para além do paradigma da Declaração de 1998 da OIT. In: SILVEIRA, Rosa Maria Godoy; DIAS, Adelaide Alves; FERREIRA, Lúcia de Fátima Guerra; FEITOSA, Maria Luiza Mayer; ZENAIDE, Maria de Nazaré. (Org.). Educação em direitos humanos: fundamentos teórico-metodológicos. João Pessoa: Editora Universitária, 2007, v. 1, p. 351-372.

Editorial: Direitos sociais e desenvolvimento. In: Prim@ Facie, v. 11, n. 20, 2012. Disponível em: <http://periodicos.ufpb.br/ojs2/index.php/primafacie/index>. Acesso em: 19 out. 2013.

DELEUZE, G. Conversações. Trad. Peter Pál Pelbart. Col. Trans. São Paulo: 34, 1992.

DELGADO, M. G. Curso de direito do trabalho. 6. ed. São Paulo: LTr, 2007.

DRUCK, G. A precarização social do trabalho no Brasil: alguns indicadores. In: ANTUNES, Ricardo. Riqueza e miséria do trabalho no Brasil II. São Paulo: Boitempo, 2013, p. 55-73.

GONÇALVES, A. F. M. Flexibilização Trabalhista. Belo Horizonte: Mandamentos, 2004.

HABERMAS, J. A nova intransparência: a crise do Estado de Bem-Estar Social e o esgotamento das energias utópicas. Trad. Carlos Alberto Marques Novaes. Novos estudos- CEBRAP, n. 18, p. 103-114,set. 1987.

HESSE, K. A força normativa da Constituição, Porto Alegre, Sérgio Antonio Fabris Editor, 1991.

JACOBS, J. A natureza das economias. Trad. Paulo Anthero Soares Barbosa. São Paulo: Beca Produções Culturais, 2001.

LARA, R. Ontologia, trabalho e serviço social. In: SARMENTO, Helder Boska de Moraes (org.). Serviço social: questões contemporâneas. Florianópolis: UFSC, 2012, p. 191-212.

LUÑO, A. E. P. Dimensiones de la igualdad. Madri: Dykinson, 2005.

MARQUES, M. C. S. Mut(il)ações das relações jurídicas de trabalho brasileiras, tese (doutorado em serviço social), 2008, 267f. Programa de Pós-graduação em Serviço Social. Universidade Federal do Rio de Janeiro, Rio de Janeiro, 2008.

MATO GROSSO. Recurso Ordinário n ${ }^{\circ}$ RO 00925.2009.003.23.00-0. Tribunal Regional do Trabalho da $23^{a}$ região, julgado em 5 abr. 2011. Disponível em: <http://trt23.jusbrasil.com.br/jurisprudencia/19148995/recurso-ordinario-trabalhista-ro-925200900323000mt-0092520090032300-0/inteiro-teor-19148996>. Acesso em: 20 fev. 2015. 
OLIVEIRA, L. J. Direito do trabalho segundo o princípio da valorização do trabalho humano.São Paulo: LTr, 2001.

ROESLER, A. R. Crise econômica, flexibilização e o valor social do trabalho. São Paulo: LTr, 2014.

ROMITA, A. S. O princípio da proteção em xeque: e outros ensaios. São Paulo: LTr, 2003.

VIE PUBLIQUE, au coer du débat public. Existe-it-il um droit au travail?França: Service-public de l'administration française, 2013. Disponível em: $<$ http://www.vie-publique.fr/decouverteinstitutions/citoyen/citoyennete/definition/droits/existe-t-il-droit-au-travail.html>. Acesso em: 10 maio 2015.

VILHENA, M. M. R. As transformações do direito do trabalho sob perspectivas socioeconômicas. In: PORTO, Elisabete Araújo (org.). Contribuições para a ciência jurídica à luz dos direitos sociais. Rio de Janeiro: Publit, 2014, p. 256-300.

WANDELLI, L. V. O direito ao trabalho como direito humano e fundamental: elementos para sua fundamentação e concretização. Tese (doutorado) Direito UFPR/CCJ, 443 f. Curitiba, 2009. 